\title{
FENOLOGIA E EXIGÊNCIA TÉRMICA DA VIDEIRA 'BENITAKA' CULTIVADA NO NORTE DE MINAS GERAIS'
}

\author{
DANILO PEREIRA RIBEIRO², CARLOS EDUARDO CORSATO ${ }^{3}$, \\ ANTÔNIO AUGUSTO NOGUEIRA FRANCO ${ }^{4}$, JOÃO PAULO LEMOS 5 , \\ RODRIGO MEIRELLES DE AZEVEDO PIMENTEL ${ }^{6}$
}

RESUMO-O emprego de índices biometeorológicos para a previsão dos estádios fenológicos tem sido amplamente utilizado no planejamento dos tratos culturais na viticultura. O objetivo deste trabalho foi caracterizar e comparar entre dois ciclos consecutivos, a duração em dias e as exigências térmicas em graus-dia de doze estádios do ciclo fenológico da videira 'Benitaka'. O estudo foi conduzido num vinhedo comercial localizado no município de Janaúba, região semiárida de Minas Gerais. As plantas, enxertadas sobre o porta-enxerto IAC 572 'Jales', foram conduzidas no sistema de latada e irrigadas por microaspersão. O acúmulo em dias e a exigência térmica (graus-dia) foram determinados em duas safras consecutivas, da data da poda até a colheita, adotando-se a temperatura de $10^{\circ} \mathrm{C}$ como temperatura de base. $\mathrm{O}$ acúmulo em dias, da poda à colheita, foi de 120 dias para a poda realizada em janeiro e de 131 dias para a poda em julho. Na poda de janeiro, as plantas acumularam 1.914 graus-dias, enquanto na poda de julho o acúmulo foi de 1.930 graus- dia.

Termos para indexação: semiárido, índice biometeorológico, uva, Vitis vinifera.

\section{PHENOLOGY AND THERMAL REQUIREMENT OF THE VINE 'BENITAKA' GROWN IN THE NORTH OF MINAS GERAIS}

\begin{abstract}
The use of biometeorological index for the prediction of phenological stages has been widely used in the planning of cultural practices in tropical vines. The objective of this study was to characterize and compare the duration (in days) and thermal requirements in degree-day of twelve stages of the phenological cycle of the vine 'Benitaka'. The study was carried out in the vineyard Santa Catarina, in the city of Janaúba, north of the state of Minas Gerais - Brazil. Grapevines grafted on the rootstock IAC 572 'Jales' were irrigated by microaspersion. The accumulation of days and thermal requirement were determined in the same plants on two consecutive pruning dates. The base temperature used for the study was $10^{\circ} \mathrm{C}$. The total length of the cycle ranged from 120 days for the vines pruned in January to 131 days for those pruned in July. The total amount of degree days for the grape pruning in January was 1914, whereas for the pruning in July was 1930.
\end{abstract}

Index terms: semiarid, biometeorological index, grape, Vitis vinifera.

${ }^{1}$ (Trabalho 050-09). Recebido em: 18-02-2009. Aceito para publicação em:27-10-2009.

${ }^{2}$ Graduando em Agronomia; Universidade Estadual de Montes Claros - UNIMONTES, Rua Reinaldo Viana, n 2630, CEP 39440000, C.P. 91, Janaúba-MG. e-mail: ribeirodp@bol.com.br

${ }^{3}$ Engenheiro Agrônomo, Dr., Professor do Centro de Ciências Agrárias da Universidade Estadual de Montes Claros - UNIMONTES, CEP 39440-000, C.P. 91, Janaúba-MG. e-mail: carlos.corsato@unimontes.br

${ }^{4}$ Graduando em Agronomia; UNIMONTES, CEP 39440-000, C.P. 91, Janaúba-MG. e-mail: antonioaugustonf@yahoo.com.br

${ }^{5}$ Graduando em Agronomia; UNIMONTES, CEP 39440-000, C.P. 91, Janaúba-MG. e-mail: agrolemos@hotmail.com

${ }^{6}$ Engenheiro Agrônomo, Dr., Pesquisador EPAMIG-CTNM, Rodovia MGT 122 km 155 CEP 39525-000; C.P. 12 - Nova Porteirinha

- MG. e-mail: rodrigomeirelles@epamig.br 
A produção de uvas de mesa em regiões tropicais, anteriormente consideradas inaptas, tem apresentado um aumento expressivo (Silva et al., 2008). O emprego da irrigação nessas regiões permite que a poda seja feita em qualquer época do ano, programando-se a safra para os períodos de melhores preços tanto no mercado interno quanto no externo. Nesse contexto, o norte de Minas Gerais tem demonstrado potencial para o cultivo dessa fruteira, tendo o perímetro irrigado de Pirapora como um dos polos brasileiros de produção de uvas de mesa. Feldberg et al. (2007 e 2008) indicaram algumas cultivares apirenas para a região. Em Janaúba, tem-se destacado a cultivar 'Benitaka', uma das mutações da cultivar 'Itália’ (Vitis vinifera L.), uva fina de mesa, com ótima aceitação no mercado interno.

O cultivo da videira tem dado excelente retorno econômico ao produtor rural, desde que a produção tenha qualidade e produtividade, o que demanda o emprego de tecnologias adequadas e o uso racional e eficiente dos insumos agrícolas (Fráguas, 2007). Falhas no sistema de produção, entre outros fatores, provocam grandes prejuízos, uma vez que a viticultura é uma atividade agrícola de custo elevado. A resposta da videira aos tratos culturais, como adubações, podas, manejo da irrigação, controle fitossanitário, entre outros, está fortemente correlacionada ao estádio fenológico da planta, no ato da sua realização. É desejável, portanto, que o viticultor conheça os diferentes estádios de desenvolvimento da cultivar de videira que está sendo cultivada, a fim de programar os tratos culturais, assegurando-se, assim, da resposta e rendimento desejados.

Os índices biometeorológicos permitem estimar a duração dos estágios de desenvolvimento das videiras, uma vez que consideram a influência dos fatores climáticos. A adoção desses índices pelo viticultor possibilita o planejamento da colheita, com a estimativa das épocas mais adequadas para se realizarem as práticas culturais. Entre os vários índices biometeorológicos com aplicação na viticultura, Sentelhas (1998) afirma que o índice térmico, também conhecido como graus-dia (GD), quer seja pela simplicidade, quer pela confiabilidade que apresenta, tem sido o mais utilizado na viticultura tropical.

A aplicação de graus-dia como indicador biometeorológico para videira tem sido estudado por diversos autores (Boliani \& Pereira, 1996; Murakami et al., 2002; Leão \& Silva, 2003; Santos et al., 2007; Chavarria et al., 2009). Segundo Murakami et al. (2002), a simples extrapolação desses índices para regiões diferentes daquelas para as quais foram estabelecidos, pode levar a resultados que não correspondam às reais necessidades térmicas da cultura no novo local. Pedro Júnior et al. (1993), avaliando a necessidade térmica em graus-dia da videira 'Niagara Rosada’ em diferentes regiões, constataram que o total de GD necessários para a planta completar o ciclo era dependente das condições climáticas do local analisado. Por esta razão, estudos que estabeleçam in loco o índice térmico da cultura são imprescindíveis para a adoção desse modelo na viticultura (Mandelli, 1984).

O objetivo deste trabalho foi caracterizar e comparar entre dois ciclos consecutivos a duração em dias e as exigências térmicas em graus-dia, da cultivar de uva fina de mesa 'Benitaka', cultivada com irrigação no norte de Minas Gerais.

O estudo foi conduzido num vinhedo comercial no município de Janaúba, norte de Minas Gerais (1547’50”'s; 43¹8’31’O; alt.: 540 m). O clima da região, segundo a classificação de Köeppen (Ometto, 1981), é o Tropical Seco do tipo Aw; com inverno seco e verão chuvoso, com índice pluviométrico anual médio de 1.074,9 mm.

O parreiral, implantado em 1999 com a variedade 'Benitaka' sobre o porta-enxerto IAC 572 'Jales', em espaçamento de 3,2 x 3,0 m, foi conduzido no sistema de latada, com aramado traçado paralelamente às linhas de plantio, a cada $50 \mathrm{~cm}$. As plantas foram manejadas com um braço primário e 14 braços secundários. Os esporões e as varas foram podados, deixando-se 3 e 9 gemas, respectivamente.

As adubações foram feitas segundo recomendação de Terra (2003), e os tratos fitossanitários, realizados preventivamente. O parreiral irrigado por microaspersão, com bailarina invertida, recebeu lâmina d'água calculada de acordo com as recomendações de Pires et al. (2003).

O estudo foi conduzido adotando-se como tratamento diferentes épocas de poda de produção, iniciando com a poda de verão, realizada em 23-012007, seguindo-se a poda de inverno, em 21-06-2007. O regulador Dormex ${ }^{\circledR}$ a 5,5\% foi aplicado após as podas, para uniformizar as brotações nas plantas.

O delineamento empregado foi o inteiramente casualizado (DIC), com 10 repetições; sendo cada unidade experimental constituída por uma planta.

Para a caracterização fenológica, foram etiquetadas duas varas de cada planta, avaliando-se um ramo reprodutivo em cada uma, através de observações visuais, a cada dois dias, seguindo a classificação proposta por Eichhorn \& Lorenz (1984). Foram considerados os seguintes estádios: gema inchada (A), gema algodão (B), brotação (C), aparecimento da inflorescência (D), inflorescência desenvolvida (E), florescimento (F), frutificação (G), chumbinho 
(H), ervilha (I), início de compactação dos cachos (J), inicio da maturação (K) e ponto de colheita (L).

A mudança de estádio fenológico foi caracterizada quando $50 \%$ dos ramos reprodutivos observados atingiram o estádio considerado. À medida que as plantas se desenvolveram, um ramo representativo de cada estádio foi fotografado. A colheita foi realizada quando $50 \%$ dos cachos concentraram o teor de sólidos solúveis totais de $14{ }^{\circ}$ Brix, determinado para cada cacho, através de refratômetro manual Atago N-1E, com o suco de uma baga basal, duas medianas e uma apical.

$\mathrm{O}$ acúmulo em dias e a exigência térmica (graus-dia) foram contabilizados desde a poda até cada um dos estádios, bem como entre dois estádios consecutivos. Os graus-dia foram somados segundo a metodologia proposta por Villa Nova et al. (1972), adotando-se a temperatura-base de $10^{\circ} \mathrm{C}$ (Sentelhas, 1998).

$\mathrm{GD}=(\mathrm{Tm}-\mathrm{Tb})+(\mathrm{TM}-\mathrm{Tm}) / 2$, para $\mathrm{Tm}>\mathrm{Tb}$;

$\mathrm{GD}=(\mathrm{TM}-\mathrm{Tb})^{2} / 2(\mathrm{TM}-\mathrm{Tm})$, para $\mathrm{Tm}<\mathrm{Tb}, \mathrm{e}$

$\mathrm{GD}=0$, para $\mathrm{Tb}>\mathrm{TM}$.

Em que:

$\mathrm{GD}$ = graus-dia;

$\mathrm{TM}$ = temperatura máxima diária $\left({ }^{\circ} \mathrm{C}\right)$;

Tm = temperatura mínima diária $\left({ }^{\circ} \mathrm{C}\right)$, e

$\mathrm{Tb}=$ temperatura-base $\left({ }^{\circ} \mathrm{C}\right)$.

Os dados foram submetidos à análise de variância, pelo teste $\mathrm{F}$, e a comparação de médias, efetuada pelo teste de Tukey, através do software estatístico SAS (SAS Institute 2000).

O acúmulo em dias, da poda até cada um dos estádios considerados, diferiu entre os ciclos de inverno e verão (Tabela 1). A duração total do ciclo em dias, representado pelo período entre poda e colheita, foi menor para o ciclo de verão (120 dias) em relação ao ciclo de inverno (131 dias). Essa diferença pode estar relacionada com a temperatura média da estação, uma vez que, no verão, a temperatura média é superior, acelerando o desenvolvimento das plantas. Resultado semelhante foi encontrado por Pedro Junior et al. (1994), estudando a fenologia da videira 'Niágara Rosada' em Jundiaí-SP, durante cinco anos. Eles observaram redução de 29 dias, em média, na duração do ciclo da poda à colheita, para a poda realizada em setembro, período mais quente, em relação àquela realizada em julho.

A duração do ciclo produtivo da videira 'Benitaka’ cultivada em Janaúba foi menor em relação aos obtidos em outras regiões produtoras no Sudeste do Brasil, e próximo aos da região Nordeste. Boliani (1994), estudando a fenologia das cultivares 'Itália’ e 'Rubi' cultivadas em Jales-SP, obteve, em três anos de estudo, um ciclo médio de 164 dias com a poda em abril. Terra et al. (1998) relataram que na região de São Miguel Arcanjo-SP, o ciclo da 'Itália' foi de 180 dias até a colheita dos cachos. No Vale do Rio São Francisco, Leão (2000) afirmou que, para a variedade 'Itália', a duração média do ciclo da poda à colheita é de 120 dias.

Murakami et al. (2002) relataram para a videira 'Itália' cultivada em Cardoso Moreira, norte do Estado do Rio de Janeiro (com temperatura média mensal entre $21,4^{\circ} \mathrm{C}$, no mês mais frio, e $27,7^{\circ} \mathrm{C}$, no mês mais quente), que o ciclo foi de 138 dias da poda à colheita para a poda realizada em abril, e de 157 dias para a poda em julho. A videira podada em abril desenvolveu-se em temperaturas mais amenas, com isso era de se esperar que esse ciclo fosse maior que o ciclo a partir de julho. No entanto, a maior duração desse último pode ter sido influenciada pela ocorrência de chuvas no período de maturação das bagas, atrasando o acúmulo de sólidos solúveis totais e, consequentemente, a colheita. Enquanto o acúmulo de dias do florescimento ao início de maturação variou apenas dois dias, entre as duas épocas de poda, eles verificaram que da maturação à colheita houve um acréscimo de 11 dias para a poda realizada em julho.

Entre os estádios fenológicos, também se observou uma duração menor em relação a outras regiões produtoras. O estádio de gema algodão (B) ocorreu sete dias após a poda de verão (Tabela 1 ). Na poda de inverno, esse estádio foi atingido após 10 dias, assemelhando-se aos 10 dias registrado por Boliani \& Pereira (1996) e por Murakami et al. (2002), para a videira 'Itália' cultivada em Jales$\mathrm{SP}$, e em Cardoso Moreira-RJ, respectivamente. O estádio de brotação (C) ocorreu de 8 a 12 dias após a poda, sendo menor que os 18 e 14 dias encontrados em Jales-SP, e em Cardoso Moreira-RJ, respectivamente. Segundo Costa Curta \& Rosseli (1980), quanto maior a temperatura no período que antecede a brotação, tanto mais precoce ela ocorre. O estádio de inflorescência (D) ocorreu de 14 a 18 dias (Tabela 1), enquanto em Cardoso Moreira-RJ, ocorreu de 22 a 21 dias com as podas realizadas em abril e julho, respectivamente. O estádio de florescimento (F) ocorreu aos 34 e 41 dias (Tabela 1), e em Cardoso Moreira-RJ, de 42 a 36 dias. O estádio de início de maturação (K) ocorreu aos 97 e 102 dias, enquanto em Cardoso Moreira-RJ, aos 106 e 98 dias. O subperíodo que mais contribuiu para a diferença na duração total do ciclo entre os dois municípios foi, do início da maturação à colheita (K-L), que somaram 23 e 28 dias em Janaúba e 40 e 51 dias em Cardoso Moreira-RJ.

O norte de Minas Gerais, com temperaturas 
médias mais elevadas (Figura 2), promove o desenvolvimento mais rápido da videira. Segundo Pedro Júnior \& Sentelhas (2003), temperaturas elevadas durante o ciclo vegetativo antecipam a maturação dos cachos. Este fato pode ser observado para a cultivar apirena 'Superior Seedless', que em regiões tropicais, como no Vale do São Francisco na Bahia (Grangeiro et al., 2002) e no Norte de Minas Gerais (Feldberg et al., 2008), apresentou duração média do ciclo de produção de 94 e 97 dias, respectivamente, enquanto , em Jaboticabal-SP, o ciclo foi de 130 dias (Leão et al., 2000).

Diferenças significativas entre os grausdia acumulados a partir das duas épocas de poda ocorreram somente nos estádios de maturação das bagas, “J”, "K” e "L” (Tabela 1) e nos subperíodos 'I-J'; 'J-K' e 'K-L' (Figura 1). Segundo Pedro Junior \& Sentelhas (2003), outros fatores, como a amplitude térmica e o comprimento do dia, podem influenciar nos processos de coloração, concentração de sólidos solúveis totais e acidez das bagas. A amplitude térmica no ciclo de verão foi de $13,2^{\circ} \mathrm{C}$. dia $^{-1}, 11,7^{\circ} \mathrm{C}_{\text {. dia }}{ }^{-1}$ e de $13,5^{\circ} \mathrm{C}$. dia $^{-1}$, respectivamente, enquanto no ciclo de inverno foi de $14,0^{\circ} \mathrm{C} . \mathrm{dia}^{-1}$, $14,3^{\circ} \mathrm{C} . \mathrm{dia}^{-1}$ e $15,2^{\circ} \mathrm{C}$.dia ${ }^{-1}$, respectivamente. Para esses subperíodos, a amplitude térmica no ciclo de verão foi de $13,2^{\circ} \mathrm{C} \cdot \mathrm{dia}^{-1}, 11,7^{\circ} \mathrm{C}$. dia ${ }^{-1}$ e de $13,5^{\circ} \mathrm{C}$. $\mathrm{dia}^{-1}$, respectivamente, enquanto no ciclo do inverno foi de $14,0^{\circ} \mathrm{C} . \mathrm{dia}^{-1}, 14,3^{\circ} \mathrm{C} . \mathrm{dia}^{-1}$ e $15,2^{\circ} \mathrm{C} \cdot \mathrm{dia}^{-1}$, respectivamente.

A exigência térmica foi eficiente para determinar a duração total do ciclo, já que a diferença de 1.914 GD no verão foi de apenas 16 GD, em relação aos 1.930 GD acumulados no inverno (Tabela 1). Essa diferença é idêntica à média acumulada por dia no subperíodo 'K-L', que foi de 16 GD.
Comparando-se os resultados da literatura que adotaram a temperatura de base 10, o somatório de graus-dia necessários para a videira 'Benitaka' completar o ciclo, em Janaúba (Tabela 1), foi próximo aos 1.990 GD encontrados por Boliani (1994) para as variedades 'Itália' e 'Rubi' cultivadas em Jales-SP. Terra et al. (1998) registraram 1.700 GD para a videira 'Itália' completar o ciclo na região de São Miguel Arcanjo-SP, enquanto Pedro Júnior \& Sentelhas (2003) registraram 1.660 GD para se prever a data de colheita em diferentes regiões produtoras de 'Itália'.

Os resultados apresentados neste trabalho são preliminares. Novas determinações devem ser feitas em outros ciclos de produção, aumentando a consistência dessas informações (Roberto et al., 2005; Santos et al., 2007) para que os produtores de 'Benitaka' da região possam utilizá-las eficientemente durante o ciclo da cultura, e estimarem com maior precisão a época de colheita da safra.

O ciclo de produção da videira 'Benitaka' cultivada em Janaúba somou 120 dias com a poda no verão e 131 dias com a poda no inverno, sendo acumulados 1.914 e 1.930 graus-dia, respectivamente. A época de poda influencia no número de dias necessários para que a videira mude o estádio fenológico. Somente a partir do estádio de início de compactação dos cachos, a época da poda influenciou no acúmulo de graus-dia.

Agradecimentos ao vinhedo Santa Catarina, por disponibilizar suas videiras para o estudo; ao Centro Tecnológico do Norte de Minas Gerais Epamig/CTNM, pela disponibilização dos dados meteorológicos; à Fundação de Amparo à Pesquisa para o Estado de Minas Gerais - FAPEMIG, pela concessão de bolsa de iniciação científica.

TABELA 1 - Acúmulo em dias e em graus-dia, da poda aos respectivos estádios fenológicos, em duas safras consecutivas da videira ‘Benitaka’ cultivada em Janaúba-MG, 2007.

\begin{tabular}{|c|c|c|c|c|c|c|c|c|c|c|c|c|c|}
\hline \multicolumn{14}{|c|}{ Estádio Fenológico } \\
\hline Poda & Data & A & B & $\mathrm{C}$ & $\mathrm{D}$ & $\mathrm{E}$ & $\mathrm{F}$ & $\mathrm{G}$ & $\mathrm{H}$ & I & $\mathrm{J}$ & $\mathrm{K}$ & $\mathrm{L}$ \\
\hline \multicolumn{14}{|c|}{ Dias } \\
\hline Verão & 23-01 & $3,9 b$ & $6,8 b$ & $8,4 b$ & $13,8 b$ & $28,6 b$ & $34,2 b$ & $37,7 b$ & $40,4 b$ & $45,9 b$ & $68,6 b$ & $96,6 b$ & $120 \mathrm{~b}$ \\
\hline Inverno & 21-06 & $6,5 \mathrm{a}$ & $9,9 a$ & $11,8 \mathrm{a}$ & $18,4 a$ & 35,3a & $41,5 a$ & $46,9 a$ & 49,3а & $55,5 a$ & $89,2 \mathrm{a}$ & $102,5 a$ & $131 \mathrm{a}$ \\
\hline \multicolumn{14}{|c|}{ Graus Dias } \\
\hline Verão & 23-01 & 70a & $115 a$ & $141 \mathrm{a}$ & $216 a$ & 449a & 536a & 593a & $636 a$ & $724 a$ & $1106 \mathrm{~b}$ & 1568a & 1914b \\
\hline Inverno & 21-06 & $86 a$ & $128 \mathrm{a}$ & $152 \mathrm{a}$ & 238a & $467 a$ & $545 a$ & $615 a$ & 648a & $731 \mathrm{a}$ & $1216 a$ & $1426 \mathrm{~b}$ & 1930a \\
\hline
\end{tabular}



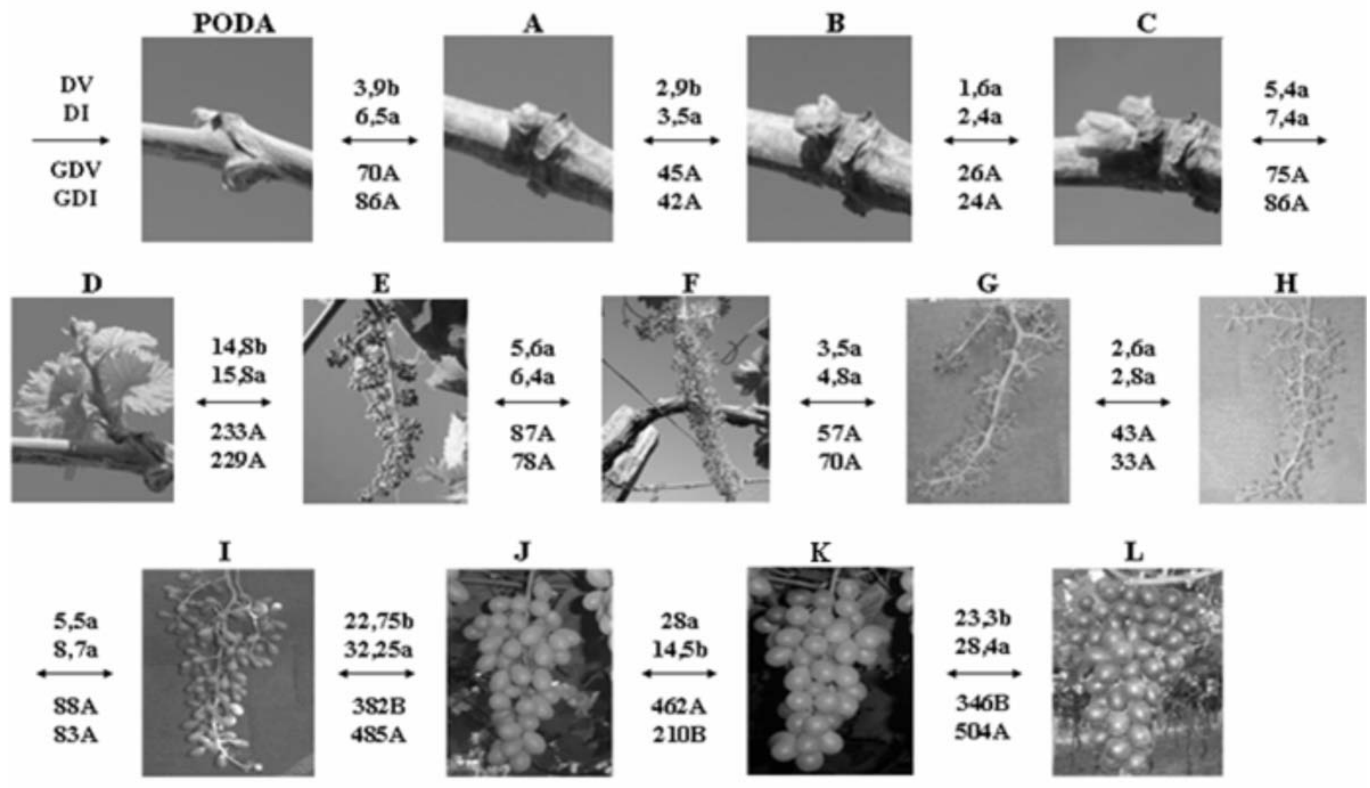

FIGURA 1 - Acúmulo em dias e exigência térmica entre os estádios fenológicos da videira 'Benitaka', a partir da data de poda, em duas safras consecutivas. Janaúba, norte de Minas Gerais, 2007.

Legenda: Acúmulo em dias no ciclo de verão (DV) e de inverno (DI). Acúmulo de Graus-dias no ciclo de verão (GDV) e de inverno (GDI). Gema inchada (A), gema algodão (B), brotação (C), aparecimento da inflorescência (D), inflorescência desenvolvida (E), florescimento (F), frutificação $(\mathrm{G})$, chumbinho $(\mathrm{H})$, ervilha $(\mathrm{I})$, início de compactação dos cachos (J), inicio da maturação (K) e colheita (L). Médias seguidas da mesma letra na coluna não diferem entre si, $(p \leq .0,05)$
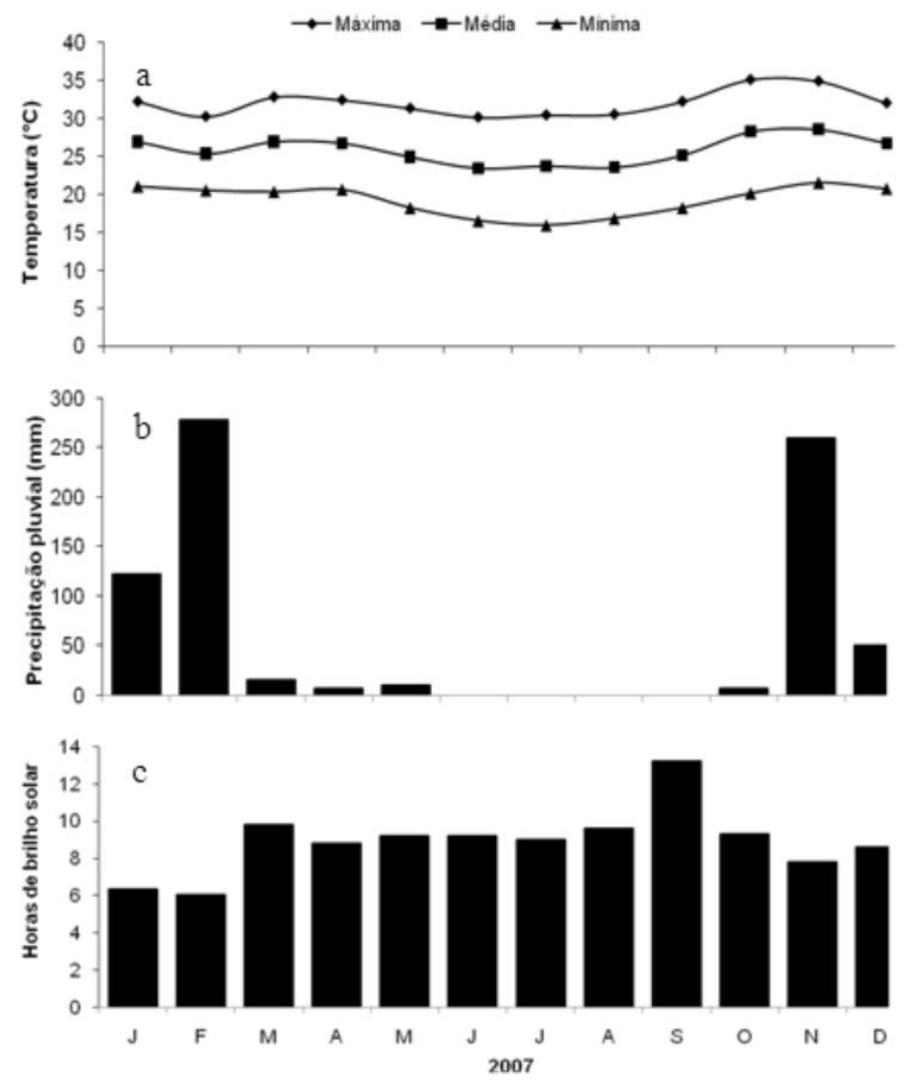

FIGURA 2 - Temperatura (a), precipitação pluvial (b) e horas de brilho solar (c), em Janaúba, norte de Minas Gerais, 2007. 


\section{REFERÊNCIAS}

BOLIANI, A.C. Avaliação fenológica de videiras Vitis vinifera L. cvs. Itália e Rubi na região oeste do Estado de São Paulo. 1994. 188f. Tese (Doutorado em Produção Vegetal) - Faculdade de Ciências Agrárias e Veterinárias. Universidade Estadual Paulista, Jaboticabal. 1994

BOLIANI, A.C.; PEREIRA, F.M. Avaliação fenológica de videiras (Vitis vinifera L.), cvs. Itália e Rubi, submetidas à poda de renovação na região oeste do Estado de São Paulo. Revista Brasileira de Fruticultura, Jaboticabal, v.18, n.2, p.193-200, 1996.

CHAVARRIA, G.; SANTOS, H. P. dos; MANDELLI, F.; MARODIN, G. A. B.; BERGAMASCHI, H.; CARDOSO, L. S. Caracterização fenológica e requerimento térmico da cultivar 'Moscato Giallo' sob cobertura plástica. Revista Brasileira de Fruticultura, Jaboticabal, v. 31, p. 119-126, 2009.

COSTA CURTA, A.; ROSSELI, G. Fattri climatici ed edafici che condizionamo gei impianti dei vignale. Revista Viticultura Enologia, Conegliano, v.10, p.469-480, 1980.

EICHHORN, K.W.; LORENZ, D.H. Phaenologische entwicklungsstadien der rebe. European and Mediterranean Plant Protection Organization, Paris, v.14, n.2, p.295-298, 1984.

FELDBERG, N. P. ; DIAS, M. S. C. ; Regina, M.A. Avaliação agronômica de cultivares de videiras apirenas na região de Jaíba, Minas Gerais. Revista Brasileira de Fruticultura, Jaboticabal, v. 30, p. 644-648, 2008.

FELDBERG, N. P. ; REGINA, M.A. ; DIAS, M. S. C. Desempenho agronômico das videiras 'Crimson Seedless’ e 'Superior Seedless' no norte de Minas Gerais. Pesquisa Agropecuária Brasileira, Brasília, v. 42, p. 777-783, 2007.

FRÁGUAS, J.C.; SONEGO, O.R.; GARRIDO, L.R.; BOTTON, M.; ALVARENGA, A.A.; ABRAHÃO, E. Uva (Vitis spp.); In: PAULA JÚNIOR, T. J. DE; VENZON, M. 101 culturas: manual de tecnologias agrícolas. Belo Horizonte: Epamig, 2007. p.769782.
GRANGEIRO, L. C. ; LEÃO, P. C. de S. ; SOARES, J. M. Caracterização fenológica e produtiva da variedade de uva 'Superior Seedless' cultivada no Vale do São Francisco. Revista Brasileira de Fruticultura, Jaboticabal, v. 24, n. 2, p. 552-554, 2002.

LEÃO, P.C.de S. Principais variedades. In: LEÃO, P.C. de S.; SOARES, J.M. (Ed.). A viticultura no semiárido brasileiro. Petrolina: EMBRAPA, 2000. p.129-142.

LEÃO, P. C. de S.; NACHTIGAL, J. C.; PEREIRA, F. M.; KOBA, V. Y. Comportamento Fenológico e produtivo das variedades de uva 'Ribol' e 'Superior Seedless’ na região de Jaboticabal, SP. Revista Brasileira de Fruticultura, Jaboticabal, v. 22, n. 2, p. 300-302, 2000.

LEÃO, P. C. de S. ; SILVA, E. E. G. Caracterização fenológica e requerimentos térmicos de variedades de uvas sem sementes no Vale do São Francisco. Revista Brasileira de Fruticultura, Jaboticabal, v. 25, n. 3, p. 379-382, 2003.

MANDELLI, F. Comportamento fenológico das principais cultivares de Vitis vinifera $\mathrm{L}$. para a região de Bento Gonçalves-RS. 1984. 125f. Dissertação (Mestrado em Agrometeorologia) - Escola Superior de Agricultura Luiz de Queiroz, Universidade de São Paulo, Piracicaba. 1984.

MURAKAMI, K. R. N.; CARVALHO, A. J. C.; CEREJA, B. S.; BARROS, J. C. S. M.; MARINHO, C. S. Caracterização fenológica da videira cv. Itália (Vitis vinifera L.) sob diferentes épocas de poda na região norte do Estado do Rio de Janeiro. Revista Brasileira de Fruticultura, Jaboticabal, v. 24, n. 3, p. 615-617, 2002.

OMETTO, J.C. Classificação Climática. In: OMETTO, J.C. Bioclimatologia tropical. São Paulo: Ceres, 1981. p.390-398.

PEDRO JÚNIOR, M. J.; SENTELHAS, P. C.; Clima e produção, In: POMMER, C.V.; Ed. UVA: tecnologia de produção, pós-colheita e mercado. Porto Alegre: Cinco Continentes, 2003. p.63-107.

PEDRO JÚNIOR, M. J.; SENTELHAS, P. C.; POMMER, C. V.; MARTINS, F. P. Determinação da temperatura-base, graus-dia e índice biometeorológico para a videira 'Niágara Rosada'. Revista Brasileira Agrometeorologia, Santa Maria, v.2, n.1, p.51-56, 1994. 
PEDRO JÚNIOR, M. J.; SENTELHAS, P. C.; POMMER, C. V.; MARTINS, F. P.; GALLO, P. B.; SANTOS, R. R. dos; BOVI, V.; SABINO, J. C. Caracterização fenológica da videira 'Niágara Rosada' em diferentes regiões paulistas. Bragantia, Campinas, v.52, n.2, p.153-160, 1993.

PIRES, R.C.M.; SAKAI, E.; BASSOI, L.H.; FUJIWARA, M. Irrigação. In: POMMER, C.V. (Ed.). Uva: tecnologia de produção, pós-colheita e mercado. Porto Alegre: Cinco Continentes, 2003. 778 p.

ROBERTO, S.R.; SATO, A.J.; BRENNER, E.A.; JUBILEU, B.S.; SANTOS, C.E.; GENTA, W. Caracterização da fenologia e exigência térmica (graus-dias) para a uva 'Cabernet Sauvignon' em zona subtropical. Acta Scientiarum. Agronomy, Maringá, v.27, n.1, p. 183-187, 2005.

SANTOS, C.E.; ROBERTO, S.R.; SATO, A.J.; JUBILEU, B.S. Caracterização da fenologia e da demanda térmica das videiras 'Cabernet Sauvignon'e 'Tannat' para a região norte do Paraná. Acta Scientiarum, Maringá, v.29, n.3, p.361-366, 2007.

SAS Institute. Sas/Stat. User's guide: statistics, versão 8.1. $4^{\text {th }}$ ed. Cary: 2002. v.2..
SENTELHAS, P.C. Aspectos climáticos para a viticultura tropical. Informe Agropecuário, Belo Horizonte, v.19, n.194. p.9-14, 1998.

SILVA, F.C.C.; VIANA, A. P.; SILVA, M. G. O. DA ; OLIVEIRA, J. G.; GOMES FILHO, A. Caracterização química e determinação dos estádios fenológicos de variedades de videiras cultivadas no Norte Fluminense. Revista Brasileira de Fruticultura, Jaboticabal, v. 30, p. 38-42, 2008.

TERRA, M.M. Nutrição, Calagem e Adubação. In: POMMER, C.V.; Ed. Uva: tecnologia de produção, pós-colheita e mercado. Porto Alegre: Cinco Continentes, 2003. p.404-476.

TERRA, M.M.; PIRES, E.J.P.; POMMER, C.V.; NOGUEIRA, N.A.M. (Coord.). Tecnologia para a produção de uva Itália na região noroeste do Estado de São Paulo. Campinas: CATI, 1998. 51 p. (Documento Técnico, 97)

VILLA NOVA, N.A.; JUNIOR, M.S.; PEREIRA, A.R.; OMETTO, J. C. Estimativa de graus-dia acumulados acima de qualquer temperatura-base em função das temperaturas máxima e mínima. Cadernos de Ciência da Terra, São Paulo, n.30, p.1-8, 1972. 